\title{
Electre Method for Determining Car Stock at PT. New Ratna Motor with a Customer Satisfaction Approach
}

\author{
Saifur Rohman Cholil ${ }^{1}$, Henny Indriyawati ${ }^{2}$, \\ ${ }^{1}$ Program Studi Sistem Informasi, Universitas Semarang \\ Jl. Soekarno Hatta Semarang, (024) 6702757, e-mail: cholil@usm.ac.id \\ 2 Program Studi Sistem Informasi, Universitas Semarang \\ JI. Soekarno Hatta Semarang, (024) 6702757, e-mail: henny@usm.ac.id
}

\section{ARTICLE INFO}

Article history:

Received 3 January 2019

Received in revised form 20 January 2019

Accepted 25 January 2019

Available online 31 January 2019

\section{ABSTRACT}

Managing car stock is the biggest challenge for a company, especially in PT. New Ratna Motor engaged in automotive. The problem is related to the process of selling goods where the sales and car stock are out of balance. Comparisons between cars entering and cars coming out (sales) are larger cars that enter so that there is a buildup of stock in the number of cars which results in company losses which include running taxes that must be paid each year, as well as the accumulation of certain types of cars and spending on car parking. The ELECTRE method is applied as a method in determining what types of cars should be stocked by the company based on customer satisfaction, if the customer is satisfied with one type / type of car and quickly gets the unit, chances are the customer will buy or reference the product. The final result of this study is the ranking of the alternatives for determining the stock of the car.

Keywords: Electre, car stock, customer satisfaction

\section{Pendahuluan}

Penjualan memegang peranan penting bagi perusahaan karena dengan banyaknya barang yang terjual akan memberikan keuntungan bagi perusahaan. Penentuan strategi dan kualitas barang yang akan dijual merupakan kunci yang diperlukan untuk meraih keuntungan dengan tingkat penjualan yang tinggi. Kepuasan pelanggan merupakan ukuran penilaian dari keberhasilan dan keberlangsungan hidup perusahaan yang wajib diperhatikan. Pelanggan yang puas dengan barang yang dibeli akan mereferensikan kepada yang lain dan ada kemungkinan untuk pembelian barang berikutnya. Kepuasan pelanggan juga berimbas pada bertambahnya pelanggan di perusahaan.

PT. New Ratna Motor adalah perusahaan bergerak dibidang otomotif yang menangani penjualan mobil merk Toyota dan penjualan spare part. PT. New Ratna Motor Semarang membawahi cabang-cabang PT. Nasmoco group untuk wilayah Jateng-DIY. Data penjualan mobil pada PT. New Ratna Motor dari bulan Januari 2018 sampai dengan Juni 2018 menunjukkan perbandingan penjulan dan jumlah stok mobil yang tidak seimbang antara mobil yang keluar dengan mobil yang masuk yang ditunjukkan pada Tabel 1. Banyaknya jumlah stok menyebabkan kerugian yang meliputi pajak berjalan yang harus dibayar perusahaan setiap tahun, menumpuknya Received January 3, 2019; Revised January 20, 2019; Accepted January 25, 2019 
jumlah tipe mobil tertentu dan pengeluaran sewa parkir mobil. Penentuan stok mobil juga berpengaruh terhadap kepuasan pelanggan, jika ada permintaan barang dan stok barang tersedia maka akan berpengaruh kepada kepuasan pelanggan.

Tabel 1. Tabel Penjualan dan stok Januari - Juni 2018

\begin{tabular}{lcc}
\hline Bulan & Jumlah Penjualan & Jumlah Stok \\
\hline Januari & 2.399 & 3.056 \\
Februai & 2.243 & 3.431 \\
Maret & 2.368 & 3.123 \\
April & 2.371 & 3.217 \\
Mei & 2.394 & 3.244 \\
Juni & 2.382 & 3.239 \\
\hline
\end{tabular}

Sistem Pendukung Keputusan (SPK) yang terkomputerisasi bisa digunakan dalam kegiatan pengambilan keputusan bagi perusahaan dengan cara mengidentifikasi dan memecahkan berbagai masalah yang ada pada perusahaan. Penyelesaian permasalahan yang menggunakan SPK diantaranya untuk pemilihan mahasiswa berprestasi menggunakan Fuzzy Multy Attribute Decission Making [1], penentuan prioritas rehabilitasi dan rekonstruksi pascabencana alam [2], penentuan konsentrasi bidang keilmuan mahasiswa yang akan mengambil tugas akhir [3]. Konsep dari metode ELECTRE (Elimination Et Choix TRaduisant la realitÉ) adalah prangkingan dengan cara membandingkan berpasangan dari alternatif pada kriteria yang telah ditentukan. Beberapa penelitian dengan menggunakan Metode ELECTRE diantaranya untuk menentukan penerimaan bantuan dana Rutilahu dari pemerintah [4], penentuan pemutusan hubungan kerja karyawan [5], menentukan penerimaan bantuan operasional penyelenggaraan Sekolah Pendidikan Anak Usia Dini [6] dan seleksi calon penyiar pada radio BOSS FM 102.8 [7].

\section{Metode Penelitian}

Metode pengambilan keputusan dengan banyak kriteria bisa diselesaikan dengan ELECTRE karena metode ini mempunyai konsep outranking dengan cara perbandingkan berpasangan dari masing-masing nilai kriteria pada alternatif yang telah ditentukan [4]. Konsep perangkingan pada metode ini yaitu apabila nilai kriteria alternatif mendominasi dibandingkan dengan nilai kriteria alternatif lain. Notasi antara 2 alternatif pada hubungan perankingan ditunjukkan sebagai $A_{k}{ }^{\circledR} A_{l}$ apablia alternatif yang ke-k tidak mendominasi dari alternatif kesecara kuantitatif, maka pengambil keputusan lebih baik mengambil resiko $A_{k}$ daripada $A_{l}$ [8]. Tahapan penyelesaian permasalahan dengan menggunakan metode ELECTRE adalah sebagai berikut [9]:

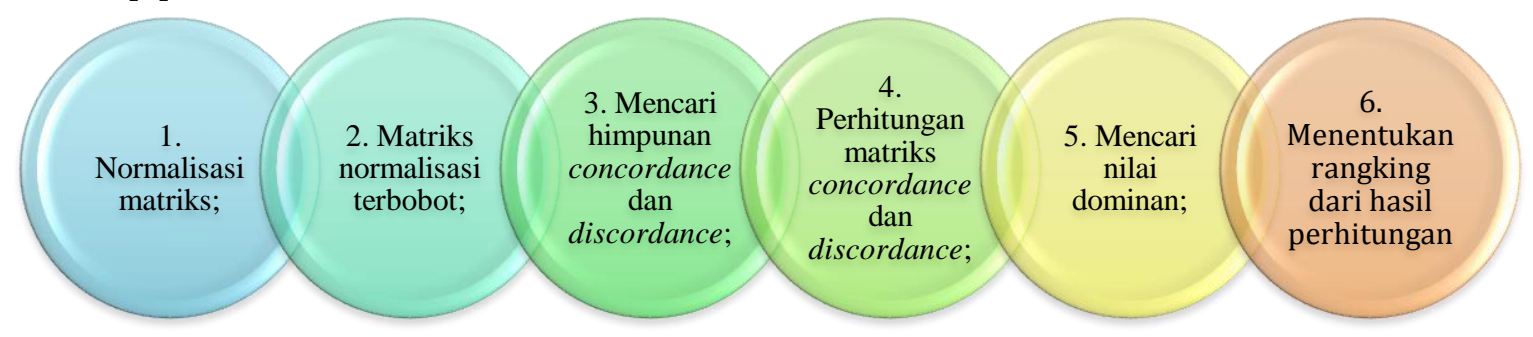

Gambar 1. Tahapan Metode Electre

1. Normalisasi matriks;

Proses normalisasi matriks keputusan dilakukan dengan menggunakan formula sebagai berikut : 


$$
r_{i j}=\frac{x_{i j}}{\sqrt{\sum_{i=1}^{m} x_{i j}^{2}}}
$$

Sehingga didapatkan matriks sebagai berikut :

$$
R=\left[\begin{array}{cccc}
r_{11} & r_{12} & \ldots & r_{1 n} \\
r_{21} & r_{22} & \ldots & r_{2 n} \\
\ldots & & & \\
r_{m 1} & r_{m 2} & \ldots & r_{m n}
\end{array}\right]
$$

2. Matriks normalisasi terbobot;

Perhitungan matriks normalisasi terbobot artinya perkalian antara matriks $\mathrm{R}$ dengan bobot $\mathrm{V}$ $=\mathrm{R} \times \mathrm{W}$. Sehingga hasil normalisasinya adalah :

$$
V=\left[\begin{array}{cccc}
v_{11} & v_{12} & \ldots & v_{1 n} \\
v_{21} & v_{22} & \ldots & v_{2 n} \\
\ldots & & & \\
v_{m 1} & v_{m 2} & \ldots & v_{m n}
\end{array}\right] R W=\left[\begin{array}{cccc}
w_{1} r_{11} & w_{2} r_{12} & \ldots & w_{n} r_{1 n} \\
w_{1} r_{21} & w_{2} r_{22} & \ldots & w_{n} r_{2 n} \\
\ldots & & & \\
w_{1} r_{m 1} & w_{2} r_{m 2} & \ldots & w_{n} r_{m n}
\end{array}\right]
$$

3. Mencari himpunan concordance dan discordance;

Pada tahapan ini perhitungan untuk mencari himpunan concordance dan discordance dilakukan dengan cara membandingkan pasangan alternatif.

Sebuah himpunan bisa dikategorikan concordance apabila :

$\mathrm{C}_{\mathrm{kl}}=\left\{\mathrm{j} \mid \mathrm{v}_{\mathrm{kj}} \geq \mathrm{v}_{\mathrm{ij}}\right\}$ untuk $\mathrm{j}=1,2,3 \ldots \mathrm{n}$

Sebuah himpunan bisa dikategorikan discordance apabila :

$\mathrm{D}_{\mathrm{kl}}=\left\{\mathrm{j} \mid \mathrm{v}_{\mathrm{kj}}<\mathrm{v}_{\mathrm{ij}}\right\}$ untuk $\mathrm{j}=1,2,3 \ldots \mathrm{n}$

4. Perhitungan matriks concordance dan discordance;

Perhitungan matriks concordance dilakukan dengan cara menjumlahkan nilai bobot yang ada pada himpunan concordance yaitu :

$$
C_{k l}=\sum_{j \in C_{k l}} w_{j}
$$

Matriks concordance dari perhitungan di atas adalah :

$$
C=\left[\begin{array}{ccccc}
- & c_{12} & c_{13} & \ldots & c_{1 n} \\
c_{21} & - & c_{23} & \ldots & c_{2 n} \\
\ldots & & & & \\
c_{m 1} & c_{m 2} & c_{m 3} & \ldots & -
\end{array}\right]
$$

Perhitungan matriks discordance dilakukan dengan cara mencari nilai maksimum dari pengurangan himpunan discordance dibagi nilai maksimum pengurangan dari semua himpunan discordance.

$$
d_{k l}=\frac{\max \left\{\left|v_{k j}-v_{l j}\right|\right\}_{j \in D_{k l}}}{\max \left\{\left|v_{k j}-v_{l j}\right|\right\}_{\nabla j}}
$$

Sehingga matriks discordance yang dihasilkan adalah :

TRANSFORMTIKA, Vol.16, No.2, Januari 2019, pp. 160 - 168 


$$
D=\left[\begin{array}{ccccc}
- & d_{12} & d_{13} & \ldots & d_{1 m} \\
d_{21} & - & d_{23} & \ldots & d_{2 m} \\
\ldots & & & & \\
d_{m 1} & d_{m 2} & d_{m 3} & \ldots & -
\end{array}\right]
$$

5. Mencari nilai dominan;

Nilai concordance dikurangi dengan nilai discordance untuk memperoleh nilai $\mathrm{E}$ atau nilai dominan. Nilai dominan (E) merupakan patokan rangking pada metode Electre untuk memperoleh keputusan terbaik.

$$
E=C_{k l}-D_{k l}
$$

6. Menentukan rangking dari hasil perhitungan.

Penentuan rangking dilakukan berdasarkan nilai terbesar dari hasil akhir perhitungan.

\section{Hasil dan Pembahasan}

Penentuan alternatif pada setiap kriteria untuk stok mobil didasarkan pada Tabel penjualan dan stok mobil dengan mengambil kriteria yaitu : Penjualan (C1); Performa mesin (C2); Servis berkala (C3); Model (C4) dan Tipe audio (C5). Alternatif yang telah ditentukan ditunjukkan oleh Tabel 2, nilai alternatif pada setiap kriteria ditunjukkan oleh Tabel 3 dan bobot pada setiap kriteria ditunjukkan oleh Tabel 4.

Tabel 2. Alternatif

\begin{tabular}{lc}
\hline \multicolumn{1}{c}{ Alternatif } & Kode \\
\hline Fortuner 2.4 VRZ A/T TRD Diesel & A1 \\
Avanza Veloz 1.5 S M/T & A2 \\
Innova 2.4 V A/T Diesel & A3 \\
Agya 1.2 G M/T TRD & A4 \\
Calya 1.2 E M/T & A5 \\
All New Rush 1.5 S M/T TRD & A6 \\
Avanza $1.3 \mathrm{G} \mathrm{M/T}$ & A7 \\
Calya $1.2 \mathrm{G} \mathrm{M} / \mathrm{T}$ & $\mathrm{A} 8$ \\
\hline
\end{tabular}

Tabel 3. Penilaian alternatif pada setiap kriteria

\begin{tabular}{lllllll}
\hline No & Alternatif & $C 1$ & $C 2$ & $C 3$ & $C 4$ & $C 5$ \\
\hline 1 & A1 & 25 & 100 & 75 & 100 & 100 \\
2 & A2 & 25 & 100 & 75 & 75 & 100 \\
3 & A3 & 25 & 100 & 75 & 50 & 100 \\
4 & A4 & 25 & 50 & 50 & 100 & 75 \\
5 & A5 & 25 & 75 & 75 & 75 & 100 \\
6 & A6 & 50 & 75 & 75 & 75 & 100 \\
7 & A7 & 75 & 100 & 100 & 75 & 100 \\
8 & A8 & 100 & 100 & 75 & 100 & 100 \\
\hline
\end{tabular}

Tabel 4. Bobot kriteria

\begin{tabular}{llc}
\hline No & \multicolumn{1}{c}{ Kriteria } & Bobot \\
\hline 1 & Penjualan (C1) & 0,35 \\
2 & Performa mesin (C2) & 0,25 \\
\hline
\end{tabular}

Electre Method for Determining Car Stock at PT. New Ratna Motor with a Customer Satisfaction 


\begin{tabular}{lll}
\hline 3 & Servis berkala (C3) & 0,20 \\
4 & Model (C4) & 0,15 \\
5 & Tipe audio (C5) & 0,05 \\
\hline
\end{tabular}

\subsection{Normalisasi matriks}

Perhitungan normalisasi matriks dilakukan dengan rumus persamaan 1 dan hasil dari perhitungannya ditunjukkan oleh Tabel 5 .

$$
\begin{aligned}
& \mathrm{C}_{1}=\sqrt{25^{2}+25^{2}+25^{2}+25^{2}+25^{2}+50^{2}+75^{2}+100^{2}} \\
&=145,774 \\
& \mathrm{~A}_{11}=25 / 145,774=0,171 \\
& \mathrm{~A}_{21}=25 / 145,774=0,171 \\
& \mathrm{~A}_{31}=25 / 145,774=0,171 \\
& \mathrm{~A}_{41}=25 / 145,774=0,171 \\
& \mathrm{~A}_{51}=25 / 145,774=0,171 \\
& \mathrm{~A}_{61}=50 / 145,774=0,343 \\
& \mathrm{~A}_{71}=75 / 145,774=0,514 \\
& \mathrm{~A}_{81}=100 / 145,774=0,686
\end{aligned}
$$

Perhitungan $\mathrm{C} 2, \mathrm{C} 3, \mathrm{C} 4, \mathrm{C} 5, \mathrm{C} 6$ dan $\mathrm{C} 7$ dengan cara yang sama dan hasilnya adalah matriks ternormalisasi $(\mathrm{R})$ dengan menggunakan persamaan 2.

Tabel 5. Normalisasi matriks

\begin{tabular}{cccccc}
\hline Alternatif & $C 1$ & $C 2$ & $C 3$ & $C 4$ & $C 5$ \\
\hline A1 & 0,171 & 0,396 & 0,349 & 0,426 & 0,364 \\
A2 & 0,171 & 0,396 & 0,349 & 0,320 & 0,364 \\
A3 & 0,171 & 0,396 & 0,349 & 0,213 & 0,364 \\
A4 & 0,171 & 0,198 & 0,232 & 0,426 & 0,273 \\
A5 & 0,171 & 0,297 & 0,349 & 0,320 & 0,364 \\
A6 & 0,343 & 0,297 & 0,349 & 0,320 & 0,364 \\
A7 & 0,514 & 0,396 & 0,465 & 0,320 & 0,364 \\
A8 & 0,686 & 0,396 & 0,349 & 0,426 & 0,364 \\
\hline \multicolumn{1}{l}{$R=$} \\
$\left.\qquad \begin{array}{llllll}0,171 & 0,396 & 0,349 & 0,426 & 0,364 \\
0,171 & 0,396 & 0,349 & 0,320 & 0,364 \\
0,171 & 0,396 & 0,349 & 0,213 & 0,364 \\
0,171 & 0,198 & 0,232 & 0,426 & 0,273 \\
0,171 & 0,297 & 0,349 & 0,320 & 0,364 \\
0,343 & 0,297 & 0,349 & 0,320 & 0,364 \\
0,514 & 0,396 & 0,465 & 0,320 & 0,364 \\
0,686 & 0,396 & 0,349 & 0,426 & 0,364\end{array}\right]$
\end{tabular}

\subsection{Matriks normalisasi terbobot}

Hasil perhitungan matriks ternormalisasi dikalikan bobot dilakukan menggunakan persamaan 3 dan hasilnya adalah sebagai berikut. 


$$
V=\left[\begin{array}{lllll}
0,060 & 0,099 & 0,070 & 0,064 & 0,018 \\
0,060 & 0,099 & 0,070 & 0,048 & 0,018 \\
0,060 & 0,099 & 0,070 & 0,032 & 0,018 \\
0,060 & 0,050 & 0,046 & 0,064 & 0,014 \\
0,060 & 0,074 & 0,070 & 0,048 & 0,018 \\
0,120 & 0,074 & 0,070 & 0,048 & 0,018 \\
0,180 & 0,099 & 0,093 & 0,048 & 0,018 \\
0,240 & 0,099 & 0,070 & 0,064 & 0,018
\end{array}\right]
$$

\subsection{Mencari himpunan concordance dan discordance}

\section{a. Concordance}

Mencari himpunan concordance dilakukan menggunakan persamaan 4 dan hasilnya sebagai berikut :

$\mathrm{C}_{12}=\mathrm{V}_{11} \geq \mathrm{V}_{21}=0,060 \geq 0,060$

$\mathrm{C}_{13}=\mathrm{V}_{11} \geq \mathrm{V}_{31}=0,060 \geq 0,060$

$\mathrm{C}_{14}=\mathrm{V}_{11} \geq \mathrm{V}_{41}=0,060 \geq 0,060$

Perhitungan $\mathrm{C}_{15}$ dan seterusnya hingga $\mathrm{C}_{87}$ dilakukan dengan cara yang sama Sehingga dihasilkan himpunan corcordance seperti pada Tabel 5.

\section{b. Discordance}

Mencari himpunan discordance dilakukan menggunakan persamaan 5 dan hasilnya sebagai berikut :

$\mathrm{D}_{12}=\mathrm{V}_{11}<\mathrm{V}_{21}=0,060<0,060$

$\mathrm{D}_{13}=\mathrm{V}_{11}<\mathrm{V}_{31}=0,060<0,060$

$\mathrm{D}_{14}=\mathrm{V}_{11}<\mathrm{V}_{41}=0,060<0,060$

Perhitungan $\mathrm{D}_{15}$ dan seterusnya hingga $\mathrm{D}_{87}$ dilakukan dengan cara yang sama Sehingga dihasilkan himpunan discordance seperti pada Tabel 6.

Tabel 6. Himpunan concordance dan discordance

\begin{tabular}{cccc}
\hline Concordance & Himpunan & Discordance & Himpunan D \\
\hline $\mathrm{C}_{12}$ & $\{1,2,3,4,5\}$ & $\mathrm{D}_{12}$ & \{\} \\
$\mathrm{C}_{13}$ & $\{1,2,3,4,5\}$ & $\mathrm{D}_{13}$ & \{\} \\
$\mathrm{C}_{14}$ & $\{1,2,3,4,5\}$ & $\mathrm{D}_{14}$ & \{\} \\
$\mathrm{C}_{15}$ & $\{1,2,3,4,5\}$ & $\mathrm{D}_{15}$ & \{\} \\
$\mathrm{C}_{16}$ & $\{2,3,4,5\}$ & $\mathrm{D}_{16}$ & $\{1\}$ \\
$\mathrm{C}_{17}$ & $\{2,4,5\}$ & $\mathrm{D}_{17}$ & $\{1,3\}$ \\
$\mathrm{C}_{18}$ & $\{2,3,4,5\}$ & $\mathrm{D}_{18}$ & $\{2,3,4,5\}$ \\
$\mathrm{C}_{21}$ & $\{1,2,3,5\}$ & $\mathrm{D}_{21}$ & $\{4\}$ \\
$\mathrm{C}_{23}$ & $\{1,2,3,4,5\}$ & $\mathrm{D}_{23}$ & \{\} \\
$\mathrm{C}_{24}$ & $\{1,2,3,5\}$ & $\mathrm{D}_{24}$ & $\{4\}$ \\
$\mathrm{C}_{25}$ & $\{1,2,3,4,5\}$ & $\mathrm{D}_{25}$ & \{\} \\
$\mathrm{C}_{26}$ & $\{2,3,4,5\}$ & $\mathrm{D}_{26}$ & $\{1\}$ \\
$\mathrm{C}_{27}$ & $\{2,4,5\}$ & $\mathrm{D}_{27}$ & $\{1,3\}$ \\
$\mathrm{C}_{28}$ & $\{2,3,5\}$ & $\mathrm{D}_{28}$ & $\{1,4\}$ \\
$\mathrm{C}_{31}$ & $\{1,2,3,5\}$ & $\mathrm{D}_{31}$ & $\{4\}$ \\
$\mathrm{C}_{32}$ & $\{1,2,3,5\}$ & $\mathrm{D}_{32}$ & $\{4\}$ \\
$\mathrm{C}_{34}$ & $\{1,2,3,5\}$ & $\mathrm{D}_{34}$ & $\{4\}$ \\
$\mathrm{C}_{35}$ & $\{1,2,3,5\}$ & $\mathrm{D}_{35}$ & $\{4\}$ \\
$\mathrm{C}_{36}$ & $\{2,3,5\}$ & $\mathrm{D}_{36}$ & $\{1,4\}$ \\
$\mathrm{C}_{37}$ & $\{2,5\}$ & $\mathrm{D}_{37}$ & $\{1,3,4\}$ \\
$\mathrm{C}_{38}$ & $\{2,3,5\}$ & $\mathrm{D}_{38}$ & $\{1,4\}$ \\
$\mathrm{C}_{41}$ & $\{1,4\}$ & $\mathrm{D}_{41}$ & $\{2,3,5\}$ \\
$\mathrm{C}_{42}$ & $\{1,4\}$ & $\mathrm{D}_{42}$ & $\{2,3,5\}$ \\
\hline
\end{tabular}

Electre Method for Determining Car Stock at PT. New Ratna Motor with a Customer Satisfaction 


\begin{tabular}{|c|c|c|c|}
\hline $\mathrm{C}_{43}$ & $\{1,4\}$ & $\mathrm{D}_{43}$ & $\{2,3,5\}$ \\
\hline $\mathrm{C}_{45}$ & $\{1,4\}$ & $\mathrm{D}_{45}$ & $\{2,3,5\}$ \\
\hline $\mathrm{C}_{46}$ & $\{4\}$ & $\mathrm{D}_{46}$ & $\{1,2,3,5\}$ \\
\hline $\mathrm{C}_{47}$ & $\{4\}$ & $\mathrm{D}_{47}$ & $\{1,2,3,5\}$ \\
\hline $\mathrm{C}_{48}$ & $\{4\}$ & $\mathrm{D}_{48}$ & $\{1,2,3,5\}$ \\
\hline $\mathrm{C}_{51}$ & $\{1,3,5\}$ & $\mathrm{D}_{51}$ & $\{2,4\}$ \\
\hline $\mathrm{C}_{52}$ & $\{1,3,4,5\}$ & $\mathrm{D}_{52}$ & $\{2\}$ \\
\hline $\mathrm{C}_{53}$ & $\{1,3,4,5\}$ & $D_{53}$ & $\{2\}$ \\
\hline $\mathrm{C}_{54}$ & $\{1,2,3,5\}$ & $\mathrm{D}_{54}$ & $\{4\}$ \\
\hline $\mathrm{C}_{56}$ & $\{2,3,4,5\}$ & $\mathrm{D}_{56}$ & $\{1\}$ \\
\hline $\mathrm{C}_{57}$ & $\{4,5\}$ & $D_{57}$ & $\{1,2,3\}$ \\
\hline $\mathrm{C}_{58}$ & $\{3,5\}$ & $\mathrm{D}_{58}$ & $\{1,2,4\}$ \\
\hline $\mathrm{C}_{61}$ & $\{1,3,5\}$ & $D_{61}$ & $\{2,4\}$ \\
\hline $\mathrm{C}_{62}$ & $\{1,3,4,5\}$ & $D_{62}$ & $\{2\}$ \\
\hline $\mathrm{C}_{63}$ & $\{1,3,4,5\}$ & $D_{63}$ & $\{2\}$ \\
\hline $\mathrm{C}_{64}$ & $\{1,2,3,5\}$ & $D_{64}$ & $\{4\}$ \\
\hline $\mathrm{C}_{65}$ & $\{1,2,3,4,5\}$ & $\mathrm{D}_{65}$ & \{\} \\
\hline $\mathrm{C}_{67}$ & $\{4,5\}$ & $D_{67}$ & $\{1,2,3\}$ \\
\hline $\mathrm{C}_{68}$ & $\{3,5\}$ & $D_{68}$ & $\{1,2,4\}$ \\
\hline $\mathrm{C}_{71}$ & $\{1,2,3,5\}$ & $D_{71}$ & $\{4\}$ \\
\hline $\mathrm{C}_{72}$ & $\{1,2,3,4,5\}$ & $D_{72}$ & \{\} \\
\hline $\mathrm{C}_{73}$ & $\{1,2,3,4,5\}$ & $\mathrm{D}_{73}$ & \{\} \\
\hline $\mathrm{C}_{74}$ & $\{1,2,3,5\}$ & $\mathrm{D}_{74}$ & $\{4\}$ \\
\hline $\mathrm{C}_{75}$ & $\{1,2,3,4,5\}$ & $\mathrm{D}_{75}$ & \{\} \\
\hline $\mathrm{C}_{76}$ & $\{1,2,3,4,5\}$ & $\mathrm{D}_{76}$ & \{\} \\
\hline $\mathrm{C}_{78}$ & $\{2,3,5\}$ & $\mathrm{D}_{78}$ & $\{1,4\}$ \\
\hline $\mathrm{C}_{81}$ & $\{1,2,3,4,5\}$ & $\mathrm{D}_{81}$ & \{\} \\
\hline $\mathrm{C}_{82}$ & $\{1,2,3,4,5\}$ & $\mathrm{D}_{82}$ & \{\} \\
\hline $\mathrm{C}_{83}$ & $\{1,2,3,4,5\}$ & $\mathrm{D}_{83}$ & \{\} \\
\hline $\mathrm{C}_{84}$ & $\{1,2,3,4,5\}$ & $\mathrm{D}_{84}$ & \{\} \\
\hline $\mathrm{C}_{85}$ & $\{1,2,3,4,5\}$ & $\mathrm{D}_{85}$ & \{\} \\
\hline $\mathrm{C}_{86}$ & $\{1,2,3,4,5\}$ & $\mathrm{D}_{86}$ & \{\} \\
\hline $\mathrm{C}_{87}$ & $\{1,2,4,5\}$ & $\mathrm{D}_{87}$ & $\{3\}$ \\
\hline
\end{tabular}

3.4. Perhitungan matriks concordance dan discordance

a. Perhitungan matriks concordance

Perhitungan matriks corcordance seperti pada persamaan 6 dan penyusunan matriksnya seperti pada persamaan 7 , sebagai berikut :

$$
\begin{aligned}
\mathrm{C}_{12} & =\mathrm{W}_{1}+\mathrm{W}_{2}+\mathrm{W}_{3}+\mathrm{W}_{4}+\mathrm{W}_{5} \\
& =0,35+0,25+0,2+0,15+0,05 \\
& =1 \\
\mathrm{C}_{13} & =\mathrm{W}_{1}+\mathrm{W}_{2}+\mathrm{W}_{3}+\mathrm{W}_{4}+\mathrm{W}_{5} \\
& =0,35+0,25+0,2+0,15+0,05 \\
& =1 \\
\mathrm{C}_{14} & =\mathrm{W}_{1}+\mathrm{W}_{2}+\mathrm{W}_{3}+\mathrm{W}_{4}+\mathrm{W}_{5} \\
& =0,35+0,25+0,2+0,15+0,05 \\
& =1
\end{aligned}
$$

Perhitungan $\mathrm{C}_{15}$ dan seterusnya hingga $\mathrm{C}_{87}$ dilakukan dengan cara yang sama Sehingga dihasilkan matriks corcordance seperti di bawah ini. 


$$
C=\left[\begin{array}{cccccccc}
- & 1 & 1 & 1 & 1 & 0,65 & 0,45 & 0,65 \\
0,85 & - & 1 & 0,85 & 1 & 0,65 & 0,45 & 0,5 \\
0,85 & 0,85 & - & 0,85 & 0,85 & 0,5 & 0,3 & 0,5 \\
0,5 & 0,5 & 0,5 & - & 0,5 & 0,15 & 0,15 & 0,15 \\
0,6 & 0,75 & 0,75 & 0,85 & - & 0,65 & 0,2 & 0,25 \\
0,6 & 0,75 & 0,75 & 0,85 & 1 & - & 0,2 & 0,25 \\
0,85 & 1 & 1 & 0,85 & 1 & 1 & - & 0,5 \\
1 & 1 & 1 & 1 & 1 & 1 & 0,8 & -
\end{array}\right]
$$

B. Perhitungan matriks discordance

Perhitungan matriks discordance seperti pada persamaan 8 dan penyusunan matriksnya seperti pada persamaan 9 , sebagai berikut :

$$
\begin{aligned}
D_{12} & =\frac{\max \{\|\}}{\max \{|0,060-0,060| ;|0,099-0,099| ;|0,070-0,070| ;|0,064-0,048| ;|0,018-0,018|\}} \\
& =\frac{0}{0,016} \\
& =0
\end{aligned}
$$

Perhitungan $D_{13}$ dan seterusnya hingga $D_{87}$ dilakukan dengan cara yang sama Sehingga dihasilkan matriks discordance sebagai berikut :

$$
D=\left[\begin{array}{cccccccc}
- & 0 & 0 & 0 & 0 & 1 & 1 & 1 \\
1 & - & 0 & 0,323 & 0 & 1 & 1 & 1 \\
1 & 1 & - & 0,646 & 0,646 & 1 & 1 & 1 \\
1 & 1 & 1 & - & 1 & 1 & 1 & 1 \\
1 & 1 & 1 & 0,646 & - & 1 & 1 & 1 \\
0,412 & 0,412 & 0,412 & 0,266 & 0 & - & 1 & 1 \\
0,133 & 0 & 0 & 0,133 & 0 & 0 & - & 1 \\
0 & 0 & 0 & 0 & 0 & 0 & 0,387 & -
\end{array}\right]
$$

\subsection{Mencari nilai dominan}

Perhitungan pencarian nilai dominan dilakukan dengan menggunakan persamaan 15 dan hasilnya terlihat pada Tabel 7 .

Tabel 7. Nilai dominan

\begin{tabular}{crrr}
\hline Alternatif & Corcordance & Discordance & Hasil \\
\hline A1 & 5,75 & 3 & 2,750 \\
A2 & 5,3 & 4,32 & 0,977 \\
A3 & 4,7 & 6,29 & $-1,592$ \\
A4 & 2,45 & 7 & $-4,550$ \\
A5 & 4,05 & 6,65 & $-2,596$ \\
A6 & 4,4 & 3,50 & 0,896 \\
A7 & 6,2 & 1,27 & 4,934 \\
A8 & 6,8 & 0,39 & 6,413 \\
\hline
\end{tabular}

\subsection{Menentukan rangking dari hasil perhitungan}

Hasil penentuan rangking dari hasil perhitungan metode Electre dapat lihat pada Tabel 8 . 


\begin{tabular}{crrrc}
\hline \multicolumn{5}{c}{ Tabel 8. Hasil rangking } \\
\hline Alternatif & Corcordance & Discordance & Hasil & Rangking \\
\hline A1 & 5,75 & 3 & 2,750 & 3 \\
A2 & 5,3 & 4,32 & 0,977 & 4 \\
A3 & 4,7 & 6,29 & $-1,592$ & 6 \\
A4 & 2,45 & 7 & $-4,550$ & 8 \\
A5 & 4,05 & 6,65 & $-2,596$ & 7 \\
A6 & 4,4 & 3,50 & 0,896 & 5 \\
A7 & 6,2 & 1,27 & 4,934 & 2 \\
A8 & 6,8 & 0,39 & 6,413 & 1 \\
\hline
\end{tabular}

\section{Kesimpulan}

Analisa menggunakan metode ELECTRE menghasilkan perangkingan penentuan stok mobil pada PT. New Ratna Motor dimana alternatif A8 terpilih sebagai ranking pertama yaitu Mobil Calya $1.2 \mathrm{G} \mathrm{M} / \mathrm{T}$. Faktor kepuasan pelanggan juga menjadi dasar dalam penentuan stok dimana mobil dengan penjualan terbanyak belum tentu menjadi tolak ukur untuk pengajuan stok mobil berikutnya.

\section{References}

[1] B. V. Christioko, H. Indriyawati, and N. Hidayati, "Fuzzy Multi-Atribute Decision Making ( FUZZY MADM ) dengan Metode SAW untuk Pemilihan Mahasiswa Berprestasi," vol. 14, no. 2, pp. 82-85, 2017.

[2] S. R. Cholil, A. P. R. Pinem, and V. Vydia, "Implementasi metode Simple Multi Attribute Rating Technique untuk penentuan prioritas rehabilitasi dan rekonstruksi pascabencana alam," vol. 4, no. 1, pp. 1-6, 2018.

[3] K. Khoirudin, M. Z. Abdillah, and S. R. Cholil, "Concentration Determination Disciplines Of Final Project Using Simple Additive Weighting ( SAW ) Method," vol. 15, no. 2, pp. 74-85, 2018.

[4] W. Fauzi, "Sistem Pendukung Keputusan Penerima Bantuan Dana Rutilahu Dengan Menggunakan Metode Electre," Semin. Nas. Teknol. Inf. dan Komun., vol. 2016, no. Sentika, pp. 2089-9815, 2016.

[5] M. Mesran, R. Rusiana, and M. Sianturi, "Decision Support System for Termination of Employment using Elimination and Choice Translation Reality Method," J. Teknol. dan Sist. Komput., vol. 6, no. 4, p. 135, 2018.

[6] P. Sianturi, M. Mesran, P. Ramadhani, and N. W. Al-Hafiz, "Sistem Pendukung Keputusan Penentuan Penerima Bantuan Operasional Penyelengaraan ( Bop ) Paud ( Pendidikan Anak Usia Dini ) Menerapkan Metode Electre ( Studi Kasus: Dinas Pendidikan Kabupaten Simalungun )," KOMIK (Konferensi Nas. Teknol. Inf. dan Komputer), vol. I, no. 1, pp. 2026, 2017.

[7] Habibah Jayanti Damanik, I. Parlina, H. S. Tambunan, and E. Irawan, "Sistem Pendukung Keputusan dalam Seleksi Penyiar Radio Boss FM 102.8 Pematangsiantar Menggunakan Metode ELECTRE," Konf. Nas. Teknol. Inf. dan Komput., vol. I, pp. 38-44, 2017.

[8] S. Kusumadewi, Fuzzy Multi- Attribute Decision Making (Fuzzy MADM). Yogyakarta: Graha Ilmu, 2006.

[9] A. Praba, R. Pinem, and P. T. Pungkasanti, "Application Elimination Et Choix Traduisant La REalité ( ELECTRE ) On Decission Support System,” vol. 15, no. 2, pp. 106-113, 2018.

TRANSFORMTIKA, Vol.16, No.2, Januari 2019, pp. 160 - 168 